\title{
Dinâmica espaço-temporal da expansão urbana de Bauru/SP
}

\begin{abstract}
A falta de planejamento urbano e ambiental unidas ao capitalismo fez com que as ações antrópicas trouxessem diversos problemas socioespacial e ambiental. A cidade de Bauru nas últimas décadas teve um grande crescimento urbano decorrente do aumento demográfico em um curto período, assim como as demais cidades brasileiras. Considerando a tendência de aumento da pressão urbana no município de Bauru/SP, foi analisada a dinâmica da urbanização no período de 1990 a 2016, associando dados de uso e ocupação da terra, com a finalidade de subsidiar o planejamento urbano e territorial. Essa análise foi realizada em 3 períodos diferentes, sendo representada em mapas dos anos de 1990, 2003 e 2016. Para prever e evitar tais acontecimentos, existem ferramentas de geotecnologia que auxiliam órgãos governamentais bem como profissionais independentes, essas são chamadas de Sistemas de Informação Geográfico (SIG). Analisar o crescimento do município de Bauru nos últimos 26 anos foi essencial para a compreensão das tendências de crescimento urbano, bem como nos setores agrários e a preservação e manejo dos recursos naturais, com a finalidade de subsidiar o planejamento urbano e territorial. Foi analisado a partir do sensoriamento remoto aliado a outras ferramentas onde foi realizada a classificação de imagens dos satélites Landsat 5 e Landsat 8 . 0 método de classificação aplicado foi o Maximum Likelihood Classification. O resultado obtido ilustrou através de mapas e tabelas uma exorbitante redução da mata nativa decorrente da expansão urbana ausente de planejamento e fiscalização entre os períodos de 1990 a 2016. Os resultados obtidos mostram que o principal responsável pela grande diminuição dos fragmentos florestais é a expansão urbana ausente de planejamento.
\end{abstract}

Palavras-chave: Gestão Urbana; Meio Ambiente; Planejamento Urbano; Uso e Ocupação do Solo; Sensoriamento Remoto.

\section{Space-temporal dynamics of the urban expansion of Bauru/SP}

The lack of urban and environmental planning connected to capitalism has led the anthropic actions to tease diverse socio-spatial and environmental problems. In the last decades, Bauru had a great urban growth due to the demographic increase in a short period, as well as the other Brazilian cities. Considering the tendency of increasing urban pressure in Bauru/SP, was analyzed the dynamics of urbanization in the period from 1990 to 2016, associating land use and occupation data, with the purpose of subsidizing urban and territorial planning. This analysis was performed in three different periods, and is represented in maps of the years of 1990, 2003 and 2016. In order to predict and avoid such events, there are geotechnology tools that assist government agencies as well as independent professionals; Geographic Information Systems (GIS) name these tools. Analyzing the growth of the municipality of Bauru in the last twenty-six years was essential for the understanding of urban growth tendencies, as well as in the agrarian sectors and in the preservation and management of natural resources, in order to subsidize urban and territorial planning. This analysis was made from remote sensing associated to other tools where the classification of images of the satellites Landsat 5 and Landsat 8 was performed. The method of classification applied was Maximum Likelihood Classification. The obtained result illustrates through maps and tables an exorbitant reduction of the native forest due to the urban expansion absent of planning and inspection between the periods of 1990 to 2016 . The results show that the main one responsible for the great reduction of the forest fragments is the urban expansion absent from planning.

Keywords: Urban Management; Environment; Urban Planning; Land Use and Occupation; Remote Sensing.

Topic: Tecnologia, Modelagem e Geoprocessamento

Reviewed anonymously in the process of blind peer.
Received: $10 / 02 / 2018$

Approved: 24/03/2018

\section{Luan Matheus Marchiori}

Universidade do Sagrado Coração, Brasil

http://lattes.cnpq.br/1231466512342741

marchiori.arquiteto@gmail.com

Anderson Antônio da Conceição Sartori (it

Universidade do Sagrado Coração, Brasil

http://lattes.cnpq.br/8834872890494956

http://orcid.org/0000-0003-1503-0678

sartori80@gmail.com

Jacqueline Priscila Olmedo

Universidade do Sagrado Coração, Brasil

http://lattes.cnpq.br/0430509559997047

o.jackie@hotmail.com

\author{
Sidnei Fonseca Guerreiro (D) \\ Universidade do Sagrado Coração, Brasil \\ http://lattes.cnpq.br/9996024122585307 \\ http://orcid.org/0000-0002-4161-5015 \\ sfguerre@gmail.com
}

Referencing this:

MARCHIORI, L. M.; SARTORI, A. A. C.; OLMEDO, J. P.; GUERREIRO, S. F. Dinâmica espaço-temporal da expansão urbana de Bauru/SP. Revista Ibero Americana de Ciências Ambientais, v.9, n.3, p.354-364, 2018. DOI: http://doi.org/10.6008/CBPC2179-6858.2018.003.0028 


\section{INTRODUÇÃO}

A atual urbanização mundial aliada ao capitalismo tem-se caracterizado pelo rápido crescimento desordenado dos grandes centros, tendo como consequência inúmeros problemas de ordem ambiental e sócio espacial. A cidade de Bauru, assim como as demais cidades brasileiras nas últimas décadas, expandiuse rapidamente. Essa expansão aconteceu principalmente após a nova ordem política e social instaurada pela ditadura militar na década de 70 , de forma que havia a necessidade de uma modernização em termos urbanísticos. De lá para cá, só houve crescimento urbano, onde a maior parte desse crescimento se caracteriza pela falta de planejamento (MARCHIORI, 2015).

Em termos ambientais, são notórios os riscos e prejuízos causados pelo crescimento desenfreado e ocupação desordenada das áreas urbanas. 0 desaparecimento da biodiversidade vegetal e animal, dos recursos hídricos, e a contaminação do meio físico são algumas das consequências da expansão urbana ao longo dos anos (ARAGÃO et al., 2017; SILVA et al., 2015; OLIVEIRA et al., 2014).

Para prever tais eventos, o estudo das dinâmicas espaço-temporal em ambientes urbanos vem sendo analisado pelas transformações do uso e cobertura de solo, torna-se essencial para o entendimento e compreensão do espaço, de forma que possibilite inferir tendências de cenários futuros, evitando consequências irreversíveis (BRANNSTROM et al., 2008).

Além de ser uma ferramenta indispensável para a prevenção de catástrofes ambientais, os Sistemas de Informação Geográfica SIG's vem sendo muito utilizados para fins de manejo de recursos naturais bem como controle e organização das cidades e seus crescimentos a nível urbano, regional, estadual e nacional através de órgãos governamentais (DIAS et al., 2008). Dentro dos SIG's, o sensoriamento remoto segundo Forster (1994), surge como uma técnica eficiente na qual avalia o processo da expansão urbana, e quando aliada a outras tecnologias, fornece a possibilidade de monitorar além do crescimento urbano, os problemas ambientais decorrentes dos processos de urbanização e agrário.

A função dos sistemas de informação geográfica (SIG) consiste em integrar as informações obtidas por sensoriamento remoto com outros dados espacialmente distribuídos (modelo numérico do terreno e declividade, entre outros). OS SIG permitem, dessa forma, criar um modelo do mundo real ao integrarem dados de natureza diversa, voltados para uma aplicação em particular. Barredo (1996) sugere que, atualmente, a alta diversificação da informação espacial e o grande volume de dados espaciais gerados pelo sensoriamento remoto tornam os SIG uma potente ferramenta de gestão desses dados.

No entanto, realizada a gestão adequada dos dados espaciais, podemos pensar que a ordenação territorial e, em particular, os múltiplos aspectos do planejamento físico-territorial, podem ser assistidos pelos SIG. Contudo, quando se delineiam os problemas frequentes na ordenação territorial como onde, quanto, a que distância e quais, surgem à necessidade de integrar ferramentas alheias aos SIG para respondêIos (FARINA, 2006; GRABSKI, 2015). Portanto, as possibilidades de utilização das técnicas expostas e a necessidade do desenvolvimento urbano compatível com a preservação ambiental podem estabelecer as 
formas a partir das quais as técnicas de geoprocessamento auxiliarão na definição de áreas adequadas à implantação e gestão de atividades urbanas.

Da perspectiva da gestão dos espaços urbanos, a questão do planejamento resgata a unidade homem/natureza. A organização territorial da sociedade envolve duas dimensões da reprodução social: as relações sociais e as relações entre sociedade e natureza que as práticas sociais causam. As relações sociais vigentes, nesse sentido, regem não apenas as relações entre os diferentes grupos e indivíduos da sociedade, mas, igualmente, as relações de interação a serem estabelecidas entre eles, como sociedade organizada e a natureza, originária ou transformada pela própria ação humana. A ausência dessa visão integradora na formulação de projetos de desenvolvimento urbano e nos processos de tomada de decisões é, em grande medida, responsável pela ação contra o meio ambiente observada, na atualidade, em muitos municípios, sendo cada vez mais urgente um planejamento urbano que considere não só a perspectiva econômico-social, mas também a ambiental (FARINA, 2006; FERREIRA et al., 2016).

O referente estudo objetiva analisar os dados da dinâmica espaço temporal ao longo de 26 anos no município de Bauru, apresentando o quão pode ser prejudicial à expansão urbana e outras ações antrópicas quando decorrentes de um modelo de desenvolvimento distinto dos padrões de sustentabilidade e meio ambiente.

\section{METODOLOGIA}

\section{Área de estudo}

O município de Bauru, interior do estado de São Paulo, localiza-se na região centro - oeste paulista e está situado na latitude $22^{\circ} 18^{\prime} 54^{\prime \prime S}$ e longitude $49^{\circ} 03^{\prime} 39^{\prime \prime} \mathrm{W}$. A vegetação original e predominante no município é a mata atlântica, porém por ação do clima e da devastação das florestas o bioma que cada vez mais vem ganhando espaço em Bauru é o Cerrado. Segundo a classificação de Köppen, a cidade possui clima do tipo Cwa, definido como tropical de altitude com diminuição de chuvas no inverno e temperatura média anual de $22,6^{\circ} \mathrm{C}$, tendo invernos secos e amenos (raramente frio de forma demasiada) e verões chuvosos com temperaturas moderadamente altas.

\section{Imagens orbitais}

Para o recobrimento do município de Bauru foram utilizadas imagens espectrais do satélite americano Landsat 5 TM e Landsat $8 \mathrm{OLI}$, cenas situadas na órbita 221 e pontos 75 e 76 . As imagens foram adquiridas gratuitamente através de download pelo site do DGI/INPE. Para realização da análise temporal do uso e ocupação do solo no município, buscou-se estudar a área com intervalo de 26 (vinte e seis anos), iniciando em 1990 e terminando em 2016, de forma a subsidiar os principais aspectos e tendências nos diferentes tipos de uso do solo. 


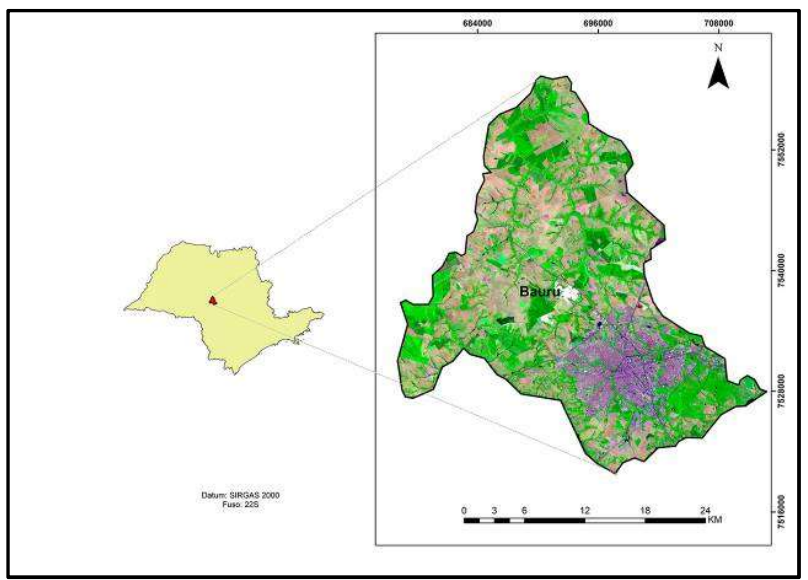

Figura 1: Localização da área do estudo - Município de Bauru/SP.

\section{Georreferenciamento das imagens}

Foram aplicadas transformações polinomiais, o que é bastante comum no registro de imagens. As transformações polinomiais fazem o vínculo entre coordenadas de imagem e as coordenadas no sistema de referência através de pontos de controle. Estes parâmetros podem ser determinados por meio de pontos de controle Ground Control Points (GCP), ou seja, feições homólogas cujas coordenadas são conhecidas na imagem e no sistema de referência de maneira a formar um sistema de equações.

\section{Classificação do uso do solo}

O método de classificação aplicado foi o Maximum Likelihood Classification. O método classificação supervisionada exige um conhecimento prévio da área de estudo, sendo necessário realizar algumas amostras do uso do solo da área de estudo. Para realizar as amostras de cada uso de solo foi criado um arquivo shape em forma de ponto, posicionando pontos de amostragem sobre os diferentes objetos e alvos, consequentemente foram estabelecidas oito classes de uso e ocupação: Área Urbana, Cultura Perene (Café, Citrus, e Cana-de-açúcar), Corpos d'água, Mata nativa, Pastagem, Reflorestamento e Solo exposto. Para a introdução dos pontos no mapa de uso e ocupação do solo foi utilizando o Google Earth como ferramenta de apoio para uma melhor definição da cobertura do solo.

Essas amostras de uso do solo foram utilizadas para treinar o sistema para reconhecer o padrão estabelecido. Então o sistema computacional comparou os pixels selecionados como amostras com os pixels contíguos, e quando o pixel contíguo é aceito, o processo continua para os demais pixels. Esse processo ocorreu até que todos os pixels da imagem estejam classificados, contidos na área de interesse. Este método de classificação parte do pressuposto que o usuário conheça previamente a área analisada, bem com a distribuição das classes, para que desta forma, quando da aplicação da classificação, a seleção de amostras de treinamento possa ser o mais eficiente possível (CRÓSTA, 1993).

\section{Modelagem espaço-temporal do uso e ocupação}

Após a classificação, foi realizada a modelagem dos diferentes uso e ocupações do solo em dois períodos, de 1990-2003 e 2003-2016, por meio do modulo Land Change Modeler-LCM, para obtenção dos 
mapas e gráficos de ganhos, perdas e persistência das classes de uso de área urbana e mata nativa, classes essenciais para a compreensão dos impactos analisados. O modulo Land Change Modeler (LCM) do Software IDRISI Selva, na qual modela as mudanças do uso do solo, permitindo identificar as mudanças no uso da terra, em termos de quantidade e na sua distribuição espacial. Estes dados e informações surgidos nos processamentos efetuados nos permitiu analisar e tomar decisões com base nas mudanças, transformações e dinâmicas impostas pela ação antrópica no espaço geográfico.

Uma característica deste módulo é o ambiente amigável em que a mesma possibilita trabalhar, haja vista que cabe ao pesquisador/usuário montar seu banco de dados e dar as coordenadas para a geração das inúmeras informações e dados. Com relação ao LCM, Demarchi et al. (2010) e Postigo et al. (2017) ressaltam que o mesmo "permite a geração de inúmeros mapas de mudanças, ganhos, perdas, persistência e transições no uso da terra entre dois períodos de tempo de maneira rápida e eficiente".

\section{RESULTADOS E DISCUSSÃO}

A partir da elaboração dos mapas de uso da terra dos anos de 1990, 2003 e 2016, foram elaboradas tabelas demostrando os dados numéricos, possibilitando a análise desses dados onde detecta e descreve as principais mudanças de uso. Os resultados das classificações estão apresentados nas Tabelas 1, 2 e 3, e nas Figuras 2, 3 e 4 respectivamente.

Tabela 1: Classes de uso do solo no município de Bauru em 1990

\begin{tabular}{|l|l|l|}
\hline Classes de Uso & Área (ha) & Porcentagem \\
\hline Área Urbana & $5.931,90$ & $8,83 \%$ \\
\hline Mata Nativa & $15.284,40$ & $22,74 \%$ \\
\hline Reflorestamento & $4.498,19$ & $6,68 \%$ \\
\hline Solo Exposto & $2.324,33$ & $3,45 \%$ \\
\hline Pastagem & $26.462,60$ & $39,34 \%$ \\
\hline Café e Citrus & $10.065,70$ & $14,96 \%$ \\
\hline Cana-de-açúcar & $2.433,42$ & $3,61 \%$ \\
\hline Corpos d'água & 263,59 & $0,39 \%$ \\
\hline
\end{tabular}

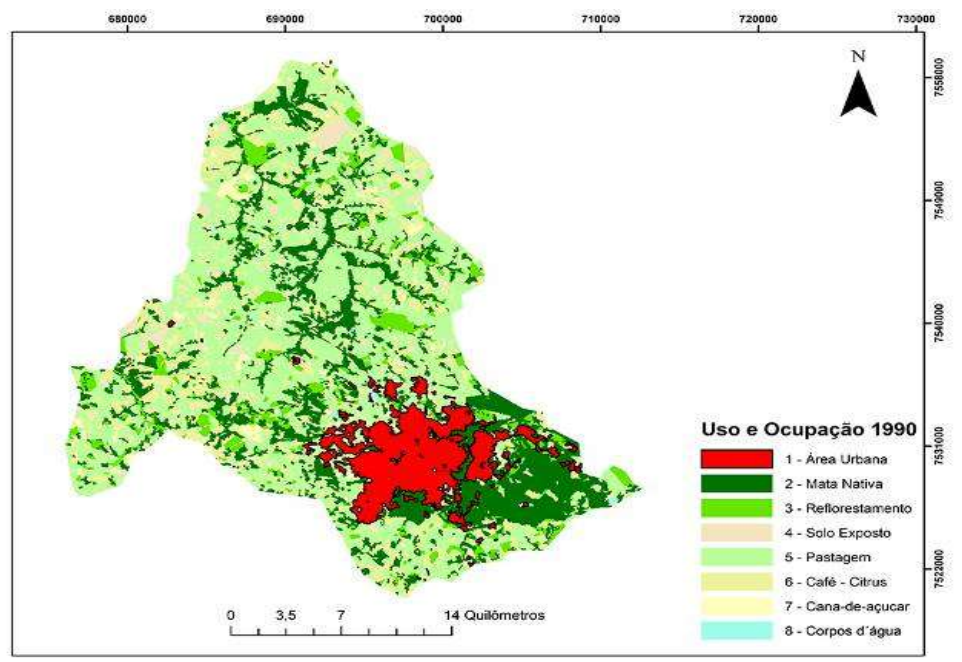

Figura 2: Mapa de uso e ocupação do solo no munícipio de Bauru em 1990.

Em 1990 foi possível observar que a área urbana ocupava 8,83\% da área total do município, e a mata nativa $22,74 \%$. Existia um importante aglomerado de mata nativa próximo à área urbana. 0 reflorestamento 
(eucalipto e pinus) era bem menos presente nesse período, e os 'braços' da mata nativa na qual compunham as bacias, eram definidos e robustos, de modo que tais corpos d'água $(0,39 \%)$ estavam quase que imperceptíveis visualmente no mapa de uso e ocupação (Tabela 1 e Figura 2).

Tabela 2: Classes de uso do solo no município de Bauru em 2003.

\begin{tabular}{|l|l|l|}
\hline Classes de Uso & Área (ha) & Porcentagem \\
\hline Área Urbana & $6.881,59$ & $10,23 \%$ \\
\hline Mata Nativa & $9.628,74$ & $14,31 \%$ \\
\hline Reflorestamento & $3.488,22$ & $5,18 \%$ \\
\hline Solo Exposto & $1.711,13$ & $2,44 \%$ \\
\hline Pastagem & $27.818,45$ & $41,15 \%$ \\
\hline Café e Citrus & $10.916,09$ & $16,58 \%$ \\
\hline Cana-de-açúcar & $6.153,52$ & $9,14 \%$ \\
\hline Corpos d'água & 665,99 & $0,97 \%$ \\
\hline
\end{tabular}

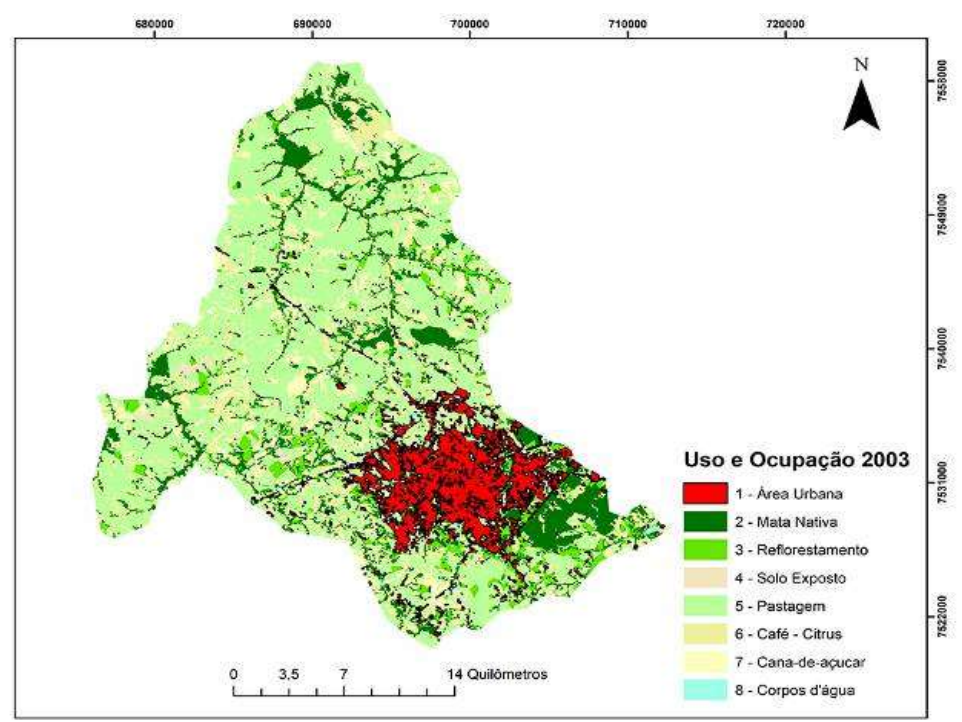

Figura 3: Mapa de uso e ocupação do solo no munícipio de Bauru em 2003.

Em 2003 (Tabela 2 e Figura 3) houve um aumento significativo na área urbana, de forma que foi possível comprova-lo através do crescimento demográfico desse período. Segundo Postigo e Sartori (2017), do final da década de 80 até o início dos anos 2000, Bauru teve um crescimento populacional de aproximadamente $34,9 \%$, fato este que, justifica a expansão urbana na qual cresceu de forma dinâmica e rápida.

Outro fato bem interessante é a oscilação do cultivo da cana-de-açúcar. Em 1990 (Figura 2 e Tabela 1), nota-se que tal cultivo compunha $3,61 \%$ da área de estudo, tendo um aumento significativo em 2003 resultando em 9,14\%. Esse valor em 2016 (Tabela 3 e Figura 4) demonstrou outra mudança ainda mais significativa, onde sua ocupação decresceu para $2,82 \%$. Isso mostra que no início dos anos 2000 , o cultivo da cana-de-açúcar estava em alta, e atualmente, na área de estudo está praticamente extinta (Tabela 3 e Figura 4). Houve também, uma grande queda de ocupação da mata nativa entre os anos de 1990 e 2003, por conta de ações antrópica (crescimento urbano e cultivo de cana de açúcar nesse período).

Tabela 3: Classes de uso do solo no município de Bauru em 2016.

\begin{tabular}{|l|l|l|}
\hline Classes de Uso & Área (ha) & Porcentagem \\
\hline Área Urbana & $9.635,85$ & $14,34 \%$ \\
\hline Mata Nativa & $9.619,49$ & $14,30 \%$ \\
\hline Reflorestamento & $7.419,57$ & $11,03 \%$ \\
\hline
\end{tabular}




\begin{tabular}{|l|l|l|}
\hline Solo Exposto & $2.404,27$ & $3,57 \%$ \\
\hline Pastagem & $26.530,20$ & $39,44 \%$ \\
\hline Café e Citrus & $9.114,98$ & $13,55 \%$ \\
\hline Cana-de-açúcar & $1.899,80$ & $2,82 \%$ \\
\hline Corpos d'água & 642,23 & $0,95 \%$ \\
\hline
\end{tabular}

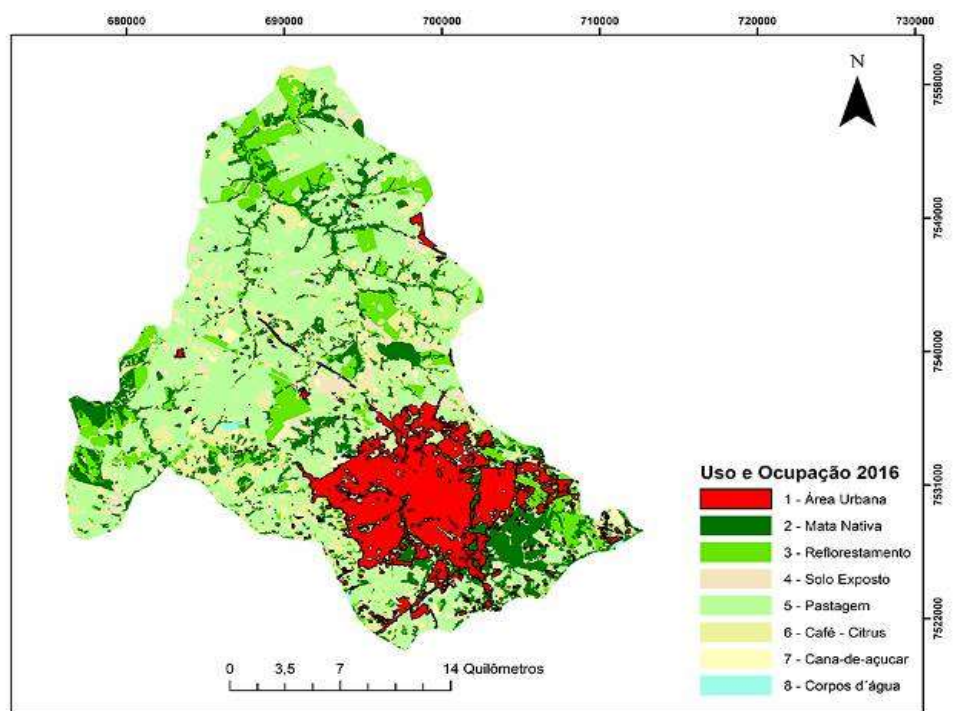

Figura 4: Mapa de uso e ocupação do solo no munícipio de Bauru em 2016

Em 2016 (Tabela 3 e Figura 4) foi possível observar que a área urbana teve um grande aumento, ocupando $14,34 \%$ da área total do município. Em relação aos fragmentos de mata nativa, houve permanência do uso quando comparado ao ano de 2003 (Tabela 2 e Figura 3), passando a ocupar 14,30\% da área total (Tabela 3 e Figura 4). O reflorestamento de eucalipto e pinus, que segundo a Indústria Brasileira de Árvores (2016), são as espécies com maior área de plantio florestal no Brasil, tornou-se mais presente em locais que outrora era ocupado por mata nativa e cana de açúcar. Pois, de acordo com Araújo (et al., 2017) a indústria madeireira de reflorestamento vem ganhando destaque a nível mundial, gerando forte influência devido a sua capacidade de substituir produtos que advém de fontes não renováveis, como combustíveis e plásticos. Contudo, em relação à pastagem, não houve grandes mudanças em nenhum dos períodos.

Os 'braços' da mata nativa no qual compõe as bacias tornaram-se mais nítidos e ausentes de vegetação, permitindo então que os corpos d'água (0,95\%) aparecessem com maior frequência visual no mapa de uso e ocupação. A partir dos dados obtidos, com base nos mapas elaborados do uso do solo, foi possível levantar a análise da expansão urbana dentro do período proposto de vinte e seis anos, como mostra as Figuras 5 e 6 e o Gráfico 1.

Percebe-se com base na Figura 5 que houve ganhos de áreas urbanas na parte norte do município, e, em contrapartida visualmente um maior número de perdas. Já na Figura 6, na qual ilustra a dinâmica espaço-temporal da área urbano entre os anos 2003 e 2016, há poucas perdas, no entanto grandes ganhos na zona sul, se comparado ao período de 1990 a 2003, sendo a localização mais saturada e cobiçada por investidores e condomínios, ou seja, a expansão urbana ocorreu de forma mais intensificada no período de 2003 a 2016. Tal incidente gera algumas consequências de mobilidade espacial, mudanças estruturais e degradação ambiental atrelada à escassez de recursos e poluição como produto da expansão urbana intensa, 
de acordo com Ojima (2016). Esses fenômenos demonstram uma alta vulnerabilidade tanto social como ambiental da fronteira urbana (BARBOSA, 2016).

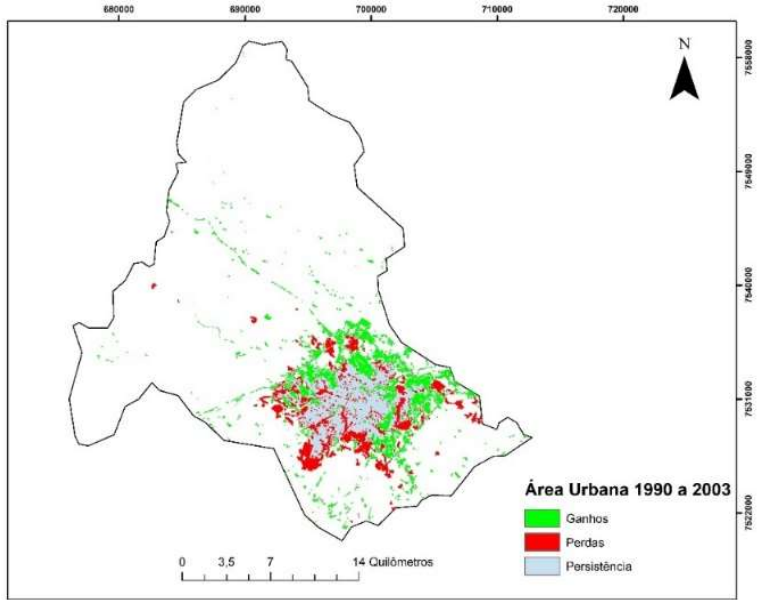

Figura 5: Variação da área urbana do munícipio de Bauru de 1990 a 2003.

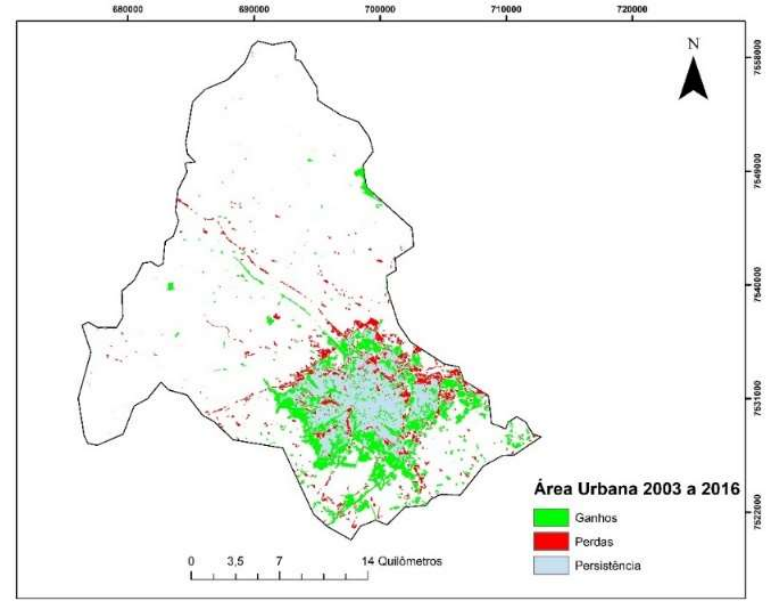

Figura 6: Variação da área urbana do munícipio de Bauru de 2003 a 2016.

Sobre o aspecto espacial e temporal percebe-se que no decorrer do primeiro ciclo de análise que foi de 1990 a 2003, a zona urbana de Bauru expandiu apropriando-se de áreas de maior impacto ambiental, o seu crescimento criou um cenário de perca de território da Mata Nativa e Pastagens existentes até então conforme Gráfico 1. Essa perca de mata nativa é capaz de impactar negativamente a condição mínima de escoamento superficial e elevar em níveis de assoreamento, colocando em risco reservatórios de águas, rios e cursos d'água em geral, bem como afetar a produção rural, desde o menor produtor até a grandes empresas (APARECIDO et al., 2016; OLIVEIRA et al., 2012).

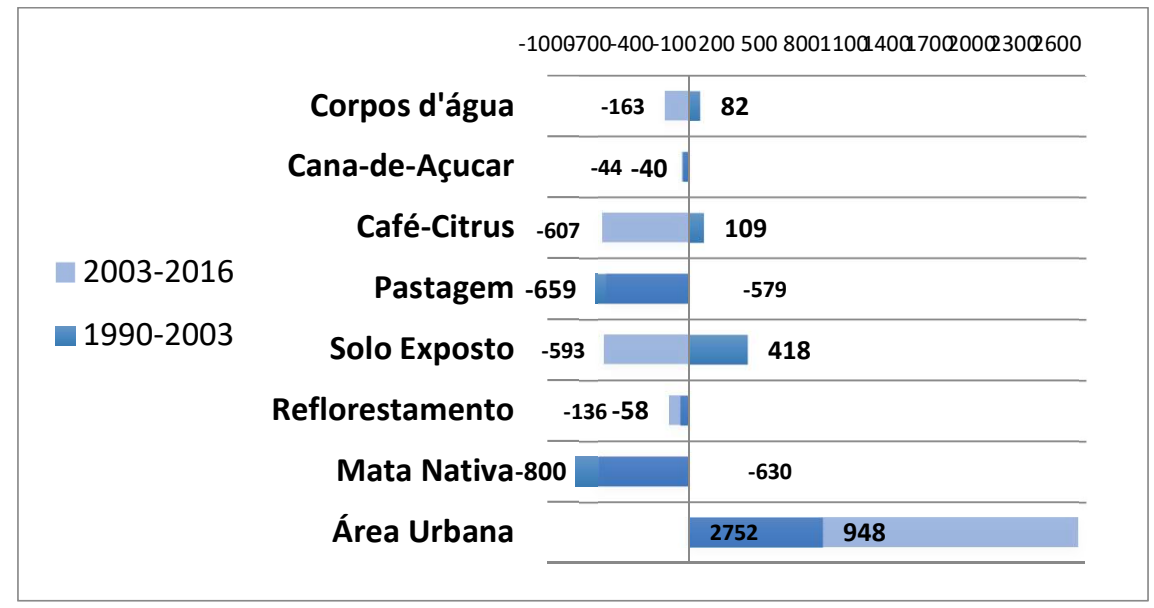

Gráfico 1: Análise espacial por classes de uso para ambos período 1990-2003 e 2003-2016 em (ha).

Esse panorama se amplificou no segundo período (2003-2016) agravando além dos citados, perca de áreas relacionadas à cultura do Café-Citrus, e mais gravemente a exposição de corpos d'água. Outros fatores que se destacaram foi o aumento da área urbana em pontos de reflorestamento no segundo período. Foi analisado outro aspecto a variabilidade espaço-temporal da mata nativa, também ao longo de 1990 a 2016, como apresenta as Figuras 7 e 8, e o Gráfico 2. 


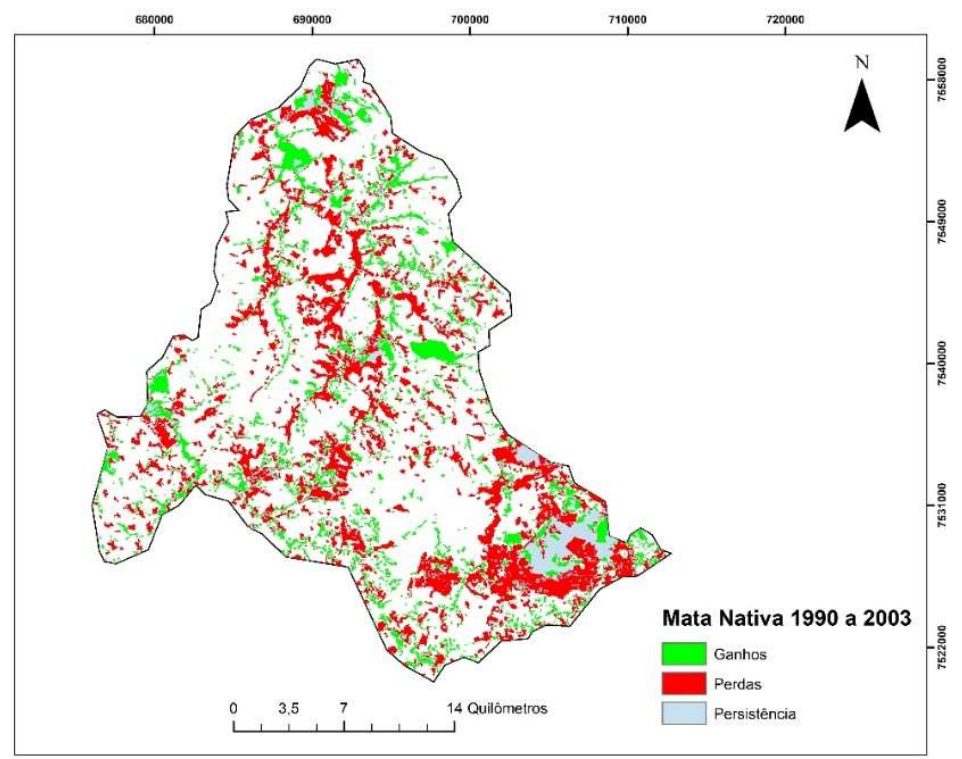

Figura 7: Variação de mata nativa do munícipio de Bauru de 1990 a 2003.

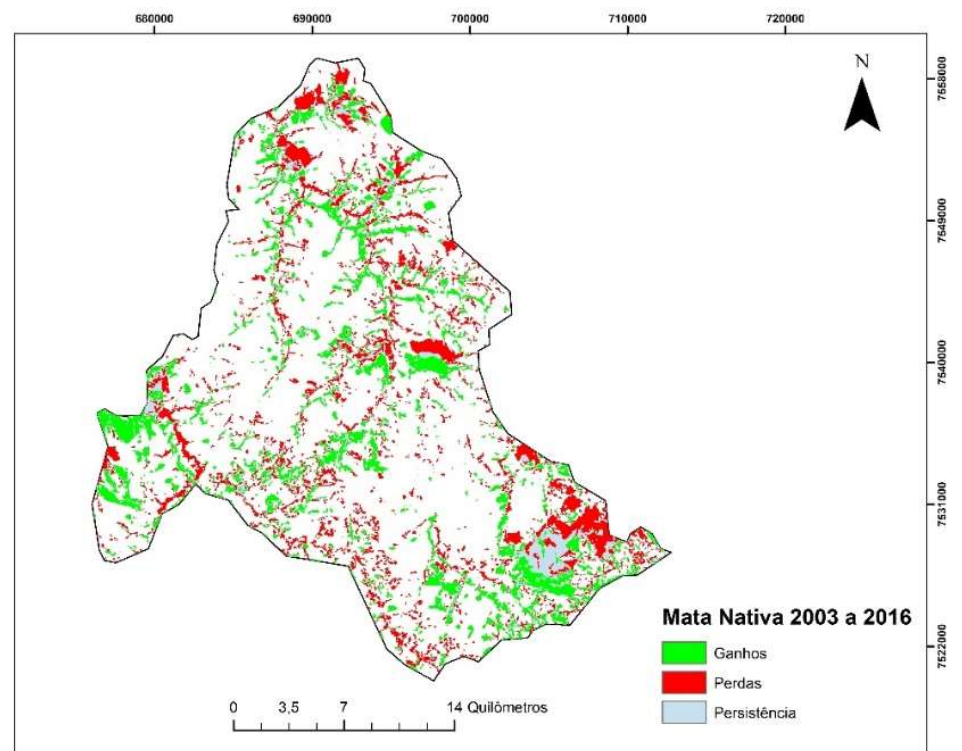

Figura 8: Variação de mata nativa do munícipio de Bauru de 2003 a 2016.

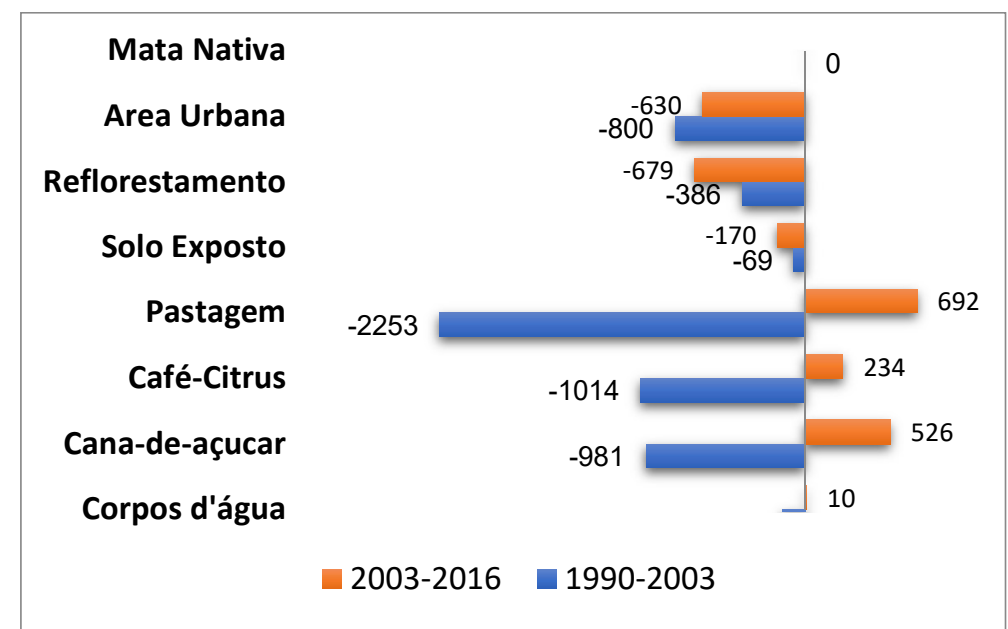

Gráfico 2: Classes que contribuíram para a mudança da mata nativa (Ha) .

A dinâmica espacial de ganhos e perdas de área da Mata Nativa em Bauru, se relacionada as demais ações antrópicas, apresentou certo recuo importante em comparação com o primeiro ciclo de analise, (1990- 
2003) ao segundo período (2003-2016). Mesmo assim, as áreas de pastagem que ocuparam grande espaço de mata nativa ainda foi o principal causador de perca territorial. Segundo Ribeiro (et al., 2015), as áreas desmatadas pode resultar em desertificação, degradação ambiental e redução da qualidade de vida, sendo as mesmas no âmbito global correspondentes à metade das matas nativas do mundo. Em contrapartida, o cultivo de Cana-de-açúcar e Café-Citrus que vinham em crescimento, a partir do segundo intervalo temporal, reduziram suas áreas, predispondo a mata nativa a retornar a sua área original. O ganho dessa vegetação é considerado um indicador de alta relevância das condições ambientais das regiões em que se localizam, pois contém funções de proteger o solo de processos erosivos, controlar o microclima, manter o nível hidrológico, bem como servir de abrigo, nidificação e alimentação de uma diversidade de espécies de animais (BREUNIG et al., 2017).

Dados relevantes gerados principalmente pela exposição do solo exposto, com o desmatamento da mata nativa, dobraram de tamanho nos dois períodos, e por fim o reflorestamento ocupou $56,84 \%$ a mais que no primeiro ciclo. De acordo com Coelho (et al., 2013), a vegetação nativa (transição de Cerrado e Mata Atlântica)no caso do município de Bauru, está sendo substituída por uma paisagem que gradualmente se encontra heterogênea, devastada e fragmentada devido as mudanças no uso e na ocupação do solo, provocadas pelas ações antrópicas.

\section{CONCLUSÕES}

Conclui-se que os dados de uso e ocupação do solo levantados, estudados e analisados nos anos de 1990, 2003 e 2016 foram essenciais para a compreensão da atual problemática que é o crescimento urbano desenfreado até atualmente no município de Bauru/SP. Por meio desses dados, foi possível visualizar a distribuição espacial dos atributos e sua dinâmica ao longo dos anos. A falta de fiscalização é um dos principais problemas se tratando de expansão urbana.

Notou-se que não houve precauções em relação à mata nativa, causando um enorme impacto ambiental negativo devido a sua redução, onde tal redução tem como principal responsável à expansão urbana sem planejamento. A produção e a aplicação de conhecimentos sobre os impactos ambientais no meio urbano são tarefas necessárias para reduzir as pressões sobre os ecossistemas. Portanto, a competência, o saber e o conhecimento técnico e científico são fundamentais para a gestão ambiental. Na sociedade da informação e do conhecimento, a pesquisa e o estudo têm o mérito de reduzir a margem de erro na tomada de decisão.

Com as ferramentas de SIG e Sensoriamento Remoto tornou-se fundamental para compreensão da dinâmica das mudanças de uso da terra. Um aspecto a ser considerado são os conhecimentos reais da paisagem a ser estuda, pois se torna fundamental na qualidade da classificação das imagens orbitais resultando nos planos de informação uso e ocupação das paisagens.

\section{REFERÊNCIAS}

APARECIDO, C. F. F.; VANZELA, L. S.; VAZQUEZ, G. H.; LIMA,

R. C.. Manejo de bacias hidrográficas e sua influência.
Revista Brasileira de Irrigação e Drenagem Irriga, Botucatu, v.21, n.2, p.239-256, 2016 
ARAGÃO, R.; CRUZ, M. A. S.; CORREIA, E. C. O.; MACHADO, L. F. M.; FIGUEIREDO, E. E.. Impacto do uso do solo pelo aumento da densidade populacional sobre o escoamento numa área urbana do Nordeste Brasileiro via geotecnologias e modelagem hidrológica. Revista Brasileira de Geografia Física, v.10, n.02, 2017.

ARAÚJO, V. A. D.; GARCIA, J. N.; BARBOSA, J. C.; GAVA, M.; SAVI, A. F.; MORALES, E. A. M.; LARH, F. A. C.; VASCONCELOS, J. S.; CHRISTOFORO, A. L.. Importância da madeira de florestas plantadas para a indústria de manufaturados. Revista de Pesquisa Florestal Brasileira, Colombo, v.37, n.90, p.189-200, 2017. DOI: http://10.4336/2017.pfb.37.90.824

BARBOSA, W. C. S.. Consequências socioambientais da expansão urbana desordenada: um estudo de caso da Vila Alto da Ressurreição, em Teresina/PI. Revista Equador (UFPI), v.5, n.3, p.162-180, 2017.

BARREDO, J. I..Sistemas de informazión geográfiza y evaluazión multizriterio en la ordenazión del territorio. Madrid: RA-MA 1996.

BRANNSTROM, C; JEPSON, W.; FILIPPI, A. M.; REDO, D.; XU, S.; GANESH, S.. Land change in the Brazilian Savanna (Cerrado), 1986-2002: Comparative analysis and implications for land-use policy. Land Use Policy, v.25, p.579-595, 2008.

BREUNIG, F. M.; BALBINOT, R.. Dinâmica de Fragmentos Florestais no Noroeste do Rio Grande do Sul. Revista Geografia, Ensino \& Pesquisa, v.21, n.1, p.177-189, 2017. DOI: http://10.5902/2236499424059

COELHO, V. H. R.; MONTENEGRO, S. M. G. L.; ALMEIDA, C. M.; LIMA, E. R. V.; NETO, A. R.; MOURA, G. S. S.. Dinâmica do uso e ocupação do solo em uma bacia hidrográfica do semiárido brasileiro. Revista Brasileira de Engenharia Agrícola e Ambiental, v.18, n.1, p.64-72, 2014.

CRÓSTA, A. P.. Processamento Digital de Imagens de Sensoriamento Remoto. Campinas: UNICAMP, 1993.

DEMARCHI, J. C.;PIROLI, E. L.. Aplicação da ferramenta land change modeler do Idrisi Taiga na análise das mudanças do uso do solo do município de Manduri, SP, entre os anos de 1990 e 2008. In: SEMINÁRIO DE ATUALIZAÇÃO EM SENSORIAMENTO REMOTO E SISTEMAS DE INFORMAÇÕES GEOGRÁFICAS APLICADOS À ENGENHARIA FLORESTAL, 9. Anais. Curitiba: FUPEF/UNICENTRO, 2010.

DIAS, E. D.; GOMES, O. V. O.; GOES, M. H. B.. O uso do geoprocessamento na determinação de áreas favoráveis a expansão urbana no município de Volta Redonda, Estado do Rio de Janeiro, Brasil. Rio de Janeiro: Instituto de Agronomia e Instituto de Geociências da Universidade Federal Rural do Rio de Janeiro, 2008.
FARINA, F. F.. Abordagem sobre as tecnicas de geoprocessamento aplicadas ao planejamento e gestão urbana. Cadernos Ebape, v.4, n.4, 2006.

FERREIRA, N. H.; FERREIRA, C. A. B. V.; GOUVEIA, I. C. M. C.. Mapa de Fragilidade Ambiental como auxílio para o Planejamento Urbano e Gestão de Recursos Hídricos. Periódico Eletrônico 'Fórum Ambiental da Alta Paulista', v.12, n.3, p.44-58, 2016. DOI: http://10.17271/1980082712320161411

FORSTER, B. C.. An examination of some problems and solutions in urban monitoring from satellite platforms. International Journal of Remote Sensing, v.6, n.1, p.139151, 1985.

GRABSKI, K.. Modelagem em SIG como Subsídio à Expansão Urbana. Dissertação (Mestrado em Geografia) Universidade Federal do Rio Grande do Sul, Porto Alegre, 2015.

OJIMA, R.. A produção e o consumo do espaço nas aglomerações urbanas brasileiras: desafios para uma urbanização sustentável. In: ENCONTRO NACIONAL DE ESTUDOS POPULACIONAIS, ABEP, 15. Anais. Caxambu, 2016.

OLIVEIRA, J. S.; CARVALHO, T. M.. Vulnerabilidade aos impactos ambientais da bacia hidrográfica do rio Cauamé em decorrência da expansão urbana e uso para lazer em suas praias. Revista Geográfica Acadêmica, v.8, n.1, p.61-80, 2014. DOI: http://10.18227/1678-7226rga.v8i1.2984

OLIVEIRA, R. G.; GIONGO, P. R.; PEREIRA, C. B. J.; VALÉRIO, F. R.; SILVA, A. O.. Identificação e frequência de espécies nativas na área de preservação permanente (APP) no córrego Campo Alegre. In: JORNADA ACADÊMICA, 6. Anais. Santa Helena de Goiás: UEG, 2012.

MARCHIORI, L. M.. Identidade da Rodoviária de Jaú e sua Importância Urbana. Iniciação Científica do curso de Graduação em Arquitetura e Urbanismo da Universidade do Sagrado Coração, 2015.

POSTIGO, M. D.; SARTORI, A. A. C. Modelagem da dinâmica do uso e ocupação do solo (1987, 2000 e 2015). Anais do XVIII Simpósio Brasileiro de Sensoriamento Remoto -SBSR, 2017.

RIBEIRO, F. L; SILVEIRA, G. R. P.; SANTOS, W. R. P.. Análise da preservação dos recursos hídricos por meio de imagem de satélite. Periódico Eletrônico 'Fórum Ambiental da Alta Paulista', v.11, n.5, p.11- 24, 2015. DOI: http://10.17271/1980082711520151179

SILVA, T. M.; CAMELLO, T. C. F.; ALMEIDA, J. R.. Impactos ambientais hidrológicos ocasionados pelo desflorestamento metropolitano: Petrópolis, RJ. Revista Sustinere, Rio de Janeiro, v.3, n.1, p.53-64, 2015. DOI: http://10.12957/sustinere.2015.17327

A CBPC - Companhia Brasileira de Produção Científica (CNPJ: 11.221.422/0001-03) detém os direitos materiais desta publicação. Os direitos referem-se à publicação do trabalho em qualquer parte do mundo, incluindo os direitos às renovações, expansões e disseminações da contribuição, bem como outros direitos subsidiários. Todos os trabalhos publicados eletronicamente poderão posteriormente ser publicados em coletâneas impressas sob coordenação da Sustenere Publishing, da Companhia Brasileira de Produção Científica e seus parceiros autorizados. Os (as) autores (as) preservam os direitos autorais, mas não têm permissão para a publicação da contribuição em outro meio, impresso ou digital, em português ou em tradução. 